\title{
Periconceptional vitamin supplementation and neural tube defects; evidence from a case-control study in Western Australia and a review of recent publications
}

\author{
Carol Bower, Fiona J Stanley
}

\begin{abstract}
Study objective-The aim was to assess the association of neural tube defects with periconceptional vitamin supplementation.

Design-This was a matched, population based case-control study.

Setting-Western Australia, 1982-1984.

Participants-Mothers of 77 cases ( $93 \%$ of those eligible) with isolated neural tube defects, mothers of 77 matched control infants with defects other than neural tube defects (control group I), and mothers of 154 liveborn, matched, control infants with no birth defects (control group II) participated in the study.
\end{abstract}

Measurements and main resultsInformation was collected by interview and self administerd questionnaire. Crude and adjusted odds ratios (and their 95\% confidence intervals) showed a small but non-significant protective effect of folate supplementation in comparisons with both control groups. The adjusted ratios for the three months before pregnancy were 0.69 $(0 \cdot 06,8 \cdot 53)$ with control group $I$, and 0.11 $(0.01,1.33)$ with control group II. In the first six weeks of pregnancy, the adjusted odds ratios were $0.70(0.32,1.52)$ with control group I and $0.74(0.29,1.88)$ with control group II. The odds ratios for vitamin supplementation of any kind were all very close to or greater than one, and all confidence intervals embraced unity.

Conclusions-These data do not provide evidence of an association between periconceptional vitamin supplementation and neural tube defects, although a protective effect of folate supplementation cannot be excluded with confidence, due to the low power of the study. Of three other observational studies of vitamins and neural tube defects, two have shown an association. While further studies of this kind may be of value, evidence must now be sought from randomised controlled trials.

Western Australian Research Institute for Child Health, Princess Margaret Hospital, Box D184, GPO Perth 6001, Western Australia C Bower

F J Stanley

Correspondence to: Dr Bower

Accepted for publication May 1991
Trials of periconceptional vitamin supplementation (either with multivitamins or folic acid) in mothers at high risk of having an infant with a neural tube defect (by virtue of having had a previously affected infant) have shown a reduction in the risk of recurrence in the mothers receiving supplementation. ${ }^{1-5}$ There have been many criticisms of these studies, ${ }^{6}$ and in any case, they did not address the issue of occurrence of infants with neural tube defects in families with no previously affected child. The issue has been addressed by three studies from the United States which have been published recently. ${ }^{7-9}$ The first two were case-control studies, one of which showed a protective effect of multivitamin supplementation in the periconceptional period, ${ }^{7}$ while the other showed no relationship between periconceptional use of vitamins and neural tube defects. ${ }^{8}$ The study by Milunsky et $a l^{9}$ was a cohort study which showed a protective effect of vitamins containing folic acid when taken in the first six weeks of pregnancy.

A case-control study in Western Australia showed that the risk of occurrence of isolated neural tube defects was associated inversely with the maternal dietary intake of folate in early pregnancy. ${ }^{10}$ Folate intake was estimated by means of a self administered questionnaire on diet and vitamin supplementation before and during pregnancy. Folate obtained by supplementation was added to the dietary estimate of folate intake for the purposes of the analysis, but periconceptional vitamin supplementation was not addressed in detail in that report. It is on the vitamin supplementation aspect of the study that the following analysis is based.

\section{Methods}

The study methods have been presented in detail elsewhere. ${ }^{10}$ In summary, all cases of neural tube defects occurring in infants born between August 1,1982 and December 31, 1984, and notified to the Western Australian Birth Defects Registry (formerly known as the Congenital Malformations Registry) ${ }^{11}$ were eligible for inclusion in the study. Cases in which the neural tube defect was diagnosed antenatally and the pregnancy terminated were also eligible for inclusion. The study was based on cases of neural defect occurring in isolation; infants with defects in addition to neural defects were excluded. Two control groups were selected. Control group I comprised liveborn and stillborn infants and terminations of pregnancy with malformations other than neural tube defects who were registered with the Birth Defects Registry. Control group II was liveborn infants without malformations selected from all pregnancies in Western Australia. One control per case was chosen to form control group I, and two controls per case were chosen for control group II. Controls were individually matched to cases on the date of the mother's last menstrual period, to account for a possible confounding effect of season, and on the date of interview, so that matched mothers were recalling periconceptional events over a similar period of time. 
Of the 83 eligible case mothers, $77(93 \%)$ participated in the study. The participation rate for control group I was $88^{\circ}{ }_{0}$ and $84^{\circ}{ }_{o}$ for control group II.

Mothers agreeing to participate in the study were interviewed by telephone to obtain information on demographic variables, pregnancy history, and family history. The two trained interviewers were unaware of the case-control status of the mothers. Interviews were conducted within 64 weeks of the last menstrual period for over $90 \%$ of cases and controls in group I, and for $85 \%$ of the mothers of subjects in control group II. All interviews were completed within 99 weeks of the last menstrual period. After the interview, mothers completed a self administered questionnaire on diet, illnesses, medications, vitamin supplements, smoking, and alcohol consumption for the period from three months before to nine months after the last menstrual period. Women were asked to specify the name of each medication and vitamin supplement, the amount of each that was taken per day, the number of days per month each was taken, and the month(s) in which each was taken. Using this information, and the date of the last menstrual period, women were categorised as taking or not taking vitamins in the three month period before pregnancy, or in the first six weeks of pregnancy. If a vitamin was taken at any time during the period of interest, women were classified as taking vitamins

Table I Association of risk of isolated neural tube defects with periconcpetional vitamin supplementation in analyses with control group I (infants with malformations other than neural tube defects)

\begin{tabular}{|c|c|c|c|c|}
\hline & \multicolumn{2}{|c|}{ Number of subjects } & \multirow{2}{*}{$\begin{array}{l}\text { Crude odds } \\
\text { ratio }\left(95^{\circ}{ }_{0} \mathrm{CI}\right)\end{array}$} & \multirow{2}{*}{$\begin{array}{l}\text { Adjusted odds }{ }^{\mathrm{a}} \\
\text { ratio }\left(95^{\circ}{ }_{o} C I\right)\end{array}$} \\
\hline & Cases & Controls & & \\
\hline $\begin{array}{l}\text { Any vitamin supplement in } \\
3 \text { month period before LMP: } \\
\text { Taken } \\
\text { Not taken }\end{array}$ & $\begin{array}{r}9 \\
66\end{array}$ & $\begin{array}{r}4 \\
73\end{array}$ & $\begin{array}{l}2 \cdot 67(0 \cdot 71,10 \cdot 05) \\
1 \cdot 00\end{array}$ & $\begin{array}{l}4 \cdot 46 \\
1 \cdot 00\end{array}(0 \cdot 79,25.20)$ \\
\hline $\begin{array}{l}\text { Folate supplement in } \\
3 \text { month period before LMP: } \\
\text { Taken } \\
\text { Not taken }\end{array}$ & $\begin{array}{r}1 \\
74\end{array}$ & $\begin{array}{r}3 \\
74\end{array}$ & $\begin{array}{l}0 \cdot 33(0 \cdot 04,3 \cdot 21) \\
1 \cdot 00\end{array}$ & $\begin{array}{l}0.69(0 \cdot 06,8 \cdot 53) \\
1.00\end{array}$ \\
\hline \multicolumn{5}{|l|}{$\begin{array}{l}\text { Any vitamin supplement in } \\
\text { first six weeks of pregnancy: }\end{array}$} \\
\hline $\begin{array}{l}\text { Taken } \\
\text { Not taken }\end{array}$ & $\begin{array}{l}23 \\
52\end{array}$ & $\begin{array}{l}24 \\
53\end{array}$ & $\begin{array}{l}1.00(0.52,1.92) \\
1.00\end{array}$ & $\begin{array}{l}0.89(0.41,1 \cdot 93) \\
1.00\end{array}$ \\
\hline $\begin{array}{l}\text { Folate suplement in } \\
\text { first six weeks of pregnancy: }\end{array}$ & & & & \\
\hline $\begin{array}{l}\text { Taken } \\
\text { Not taken }\end{array}$ & $\begin{array}{l}11 \\
64\end{array}$ & $\begin{array}{l}16 \\
61\end{array}$ & $\begin{array}{l}0.71(0 \cdot 32,1 \cdot 61) \\
1.00\end{array}$ & $\begin{array}{l}0 \cdot 70(0 \cdot 32,1 \cdot 52) \\
1 \cdot 00\end{array}$ \\
\hline
\end{tabular}

Table II Association of risk of isolated neural tube defects with periconceptional vitamin supplementation in analyses with control group II (infants with no birth defects)

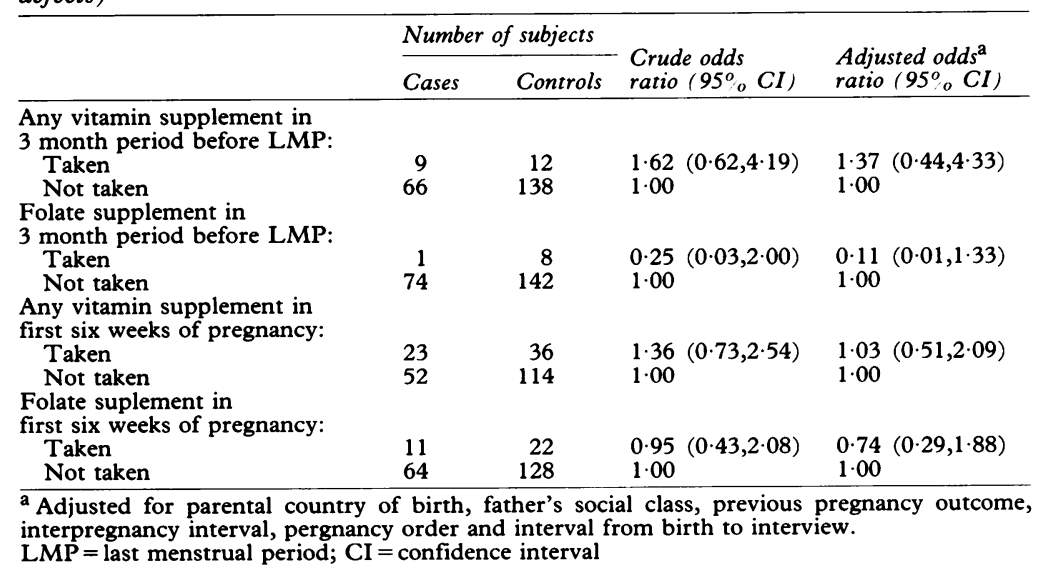

in that period. Classification of mothers was undertaken without knowledge of their casecontrol status.

In addition, information on postpartum diet, medications, and vitamin supplementation was obtained by self administered questionnaire, and women were categorised as taking or not taking vitamins postpartum. Because of our particular interest in folate, women were also classified as taking or not taking folate supplements in the same periods of interest.

Crude and adjusted odds ratios and their $95^{\circ}$ o confidence intervals were calculated by conditional logistic regression using the statistical package Epilog (Epicenter Software, Version 3, Pasadena, California, USA). The reference category in all instances was the "not taken" category. Potential confounding variables which were identified in the earlier study were used to calculate the adjusted odds ratios. ${ }^{10}$ For analyses with control group II, adjustment was made for paternal country of birth, maternal country of birth, paternal social class, previous pregnancy outcome, interpregnancy interval, pregnancy order, and interval from birth to interview. For analysis with control group I, the odds ratios were adjusted for interpregnancy interval, pregnancy order, nausea in the first trimester, and the interval from last menstrual period to interview.

Questionnaires relating to the periconceptional period were not completed by two case mothers and the mothers of four controls in group II, and two case mothers and five control mothers in group II did not complete a postpartum questionnaire. Subjects with missing data have been omitted.

\section{Results}

In the three months before pregnancy, nine case mothers $(12 \%)$ were taking one or more vitamin supplements (including folate), as were four mothers in control group I $\left(5^{\circ}{ }_{0}\right)$ and 12 mothers in control group II $(8 \%)$. In the first six weeks of pregnancy, at least one vitamin supplement was taken by 23 case mothers $\left(31^{\circ}{ }_{0}\right), 24$ mothers in control group I $(31 \%)$ and 36 mothers in control group II $(24 \%)$ (tables I and II). The most commonly taken vitamins were multivitamins or B group vitamins.

The adjusted odds ratios (and $95^{\circ}{ }_{0}$ confidence intervals) for any supplement compared with no supplement during the three months before pregnancy was $4.46(0.79,25.20)$ for control group I and 1.37 (0.44, 4.33) for control group II. During the first six weeks of pregnancy, the adjusted odds ratios (and $95^{\circ}{ }_{0}$ confidence intervals) for any vitamin supplements compared with no supplements were $0.89(0.41,1.93)$ for control group I and $1.03(0.51,2.09)$ for control group II.

Only one case mother took folate supplements in the three month period before pregnancy, compared with three mothers from control group I (adjusted odds ratio $0.69,95^{\circ}{ }_{0}$ CI $0.06,8.53$ ) and eight mothers from control group II (adjusted odds ratio $0 \cdot 11,95^{\circ}{ }_{0} \mathrm{CI} 0.01,1 \cdot 33$ ) (tables I and II). In the first six weeks of pregnancy, folate supplements were taken by 11 case mothers $(15 \%), 16$ mothers in control group I $\left(21^{\circ}{ }_{0}\right)$, and 
22 mothers in control group II $(15 \%)$. The adjusted odds ratios (and their $95^{\circ}{ }_{0}$ confidence intervals) for folate supplementation compared with no folate supplementation in this period were $0.70(0.32,1.52)$ with control group I and 0.74 $(0 \cdot 29,1 \cdot 88)$ with control group II (tables I and II). Very few multivitamin supplements contained folic acid, and most women taking folic acid took it in combination with iron.

In postpartum period, more case than control mothers were taking vitamin supplementation, most of whom were taking a folate supplementation. The folate supplement was more commonly taken with other vitamins; similar proportions of mothers were taking folate supplements in isolation (table III).

\section{Discussion}

Analysis of this population based case-control study of occurrent, isolated neural tube defects has shown a small but non-significant protective effect of folate supplementation in the three months before pregnancy, and to a lesser extent, in the first six weeks of pregnancy. Any vitamin supplementation in the prepregnancy period was more common in case than in control mothers. In the first six weeks of pregnancy, vitamin supplementation was reported to a similar degree by case and control mothers.

The finding of a protective effect of folate supplementation but not of vitamin supplementation in general is consistent with folate being an important factor in the aetiology of neural tube defects. However, the differences observed with periconceptional folate supplementation were not statistically significant, and the association may simply be due to chance. To detect a halving of the odds ratio, given the prevalence of exposure to folate supplementation in the controls, a study of this size has a power of only $12 \%$ to $34 \%$ (depending on which control group and which periconceptional period was considered). Nevertheless, the association with folate but not vitamins in general is consistent in each of the periconceptional periods, and with both control groups, which argues against a chance phenomenon.

The high participation rates, the similarity of participants and non-participants, and the blindness of the interviewers to the case-control status of the mothers suggest that participation bias and interviewer bias were unlikely. However, recall bias may account for the difference between cases and controls in reported folate supplementation. The study was designed to reduce (or to provide the means to observe) the effect of recall bias, firstly by not spelling out the hypotheses to the study mothers, secondly by matching the mothers of case and control subjects by the date of the last menstrual period and by the

Table III Postpartum vitamin supplements taken by mothers of isolated cases of neural tube defects and their matched controls

\begin{tabular}{llll}
\hline & Cases & $\begin{array}{l}\text { Control } \\
\text { Group I } \\
\text { (other defects) }\end{array}$ & $\begin{array}{l}\text { Control } \\
\text { Group II } \\
\text { (no defects) }\end{array}$ \\
\hline $\begin{array}{l}\text { Any vitamin supplement } \\
\text { Folate supplement }\end{array}$ & $18(24)^{\circ}{ }_{0}$ & $13\left(17^{\circ}{ }^{\circ}\right)$ & $20\left(13^{\circ}{ }_{0}\right)$ \\
with other vitamins & $14\left(19^{\circ}{ }_{0}\right)$ & $9\left(12^{\circ}\right)$ & $9\left(6^{\circ}{ }_{0}\right)$ \\
folate alone & $11\left(15^{\circ}\right)$ & $4\left(5^{\circ}{ }_{0}\right)$ & $3\left(2^{\circ}\right)$ \\
\hline
\end{tabular}

time of interview, such that mothers were recalling events over a similar period of time, and thirdly by having one control group of infants with other malformations. The differences in odds ratios between analyses with control group I and control group II were small, suggesting that recall was similar in both control groups.

Many vitamin preparations in Western Australia are purchased over the counter, and hence no attempt was made to validate the mothers' recall of vitamin use. Most mothers, however, reported the brand name and daily dose clearly. Of more concern was exactly when the supplements were taken, and we had no way of checking this. Most folate supplements taken were in the form of an iron-folate preparation, which is very commonly taken during pregnancy, but not at other times. If supplementation with this preparation was usually begun after completion of the first six of pregnancy, and case mothers were accurate in their recall, but control mothers (erroneously) reported beginning the supplement earlier, then the resulting misclassification would bias the odds ratios in the direction of the protective effect which has been observed in this study. A misclassification of this kind has also been suggested as a possible explanation for the findings in the study of Milunsky et $a l^{9}$ (see below).

Most case mothers had received genetic counselling by the time they participated in the study. Genetic counselling at the time the study was conducted included a discussion of the potential role of vitamin supplementation in the prevention of neural tube defects. However, folic acid was not solely implicated, and it was suggested that if any supplementation were to be taken, it should be a multivitamin preparation containing folate. Certainly, more case than control mothers were taking vitamin supplements postpartum, and although folate supplements were taken by more case mothers they were most frequently taken in conjunction with other vitamins. This evidence that case mothers were not selectively taking folate supplements postpartum suggests that they would not have selectively recalled not taking periconceptional folate supplements in the belief that folate alone may have been the important nutrient. Case mothers reported taking any vitamin supplements more frequently than mothers in either of the control groups, which also seems surprising if their recall had been biased by the information they had received at the time of genetic counselling.

A case-control study of central nervous system anomalies and drugs prescribed in the three months before pregnancy and during the first trimester of pregnancy ${ }^{12}$ found odds ratios which were less than unity for all folate containing prescriptions in the first trimester $\left(0 \cdot 75,95^{\circ}{ }_{0} \mathrm{CI}\right.$ $0.59,0.93)$ and in the three months before conception $(0 \cdot 14,95 \%$ CI $0 \cdot 003,1 \cdot 11)$. There was also a suggestion of a greater protective effect the earlier in pregnancy the supplement was started. These odds ratios are of a similar order of magnitude to those in the present study. The results related to all nervous system defects, not just neural tube defects, and hence the effect may have been diluted by inclusion of cases having no 
association with folate. Mothers may not have taken the prescribed drugs, or may have obtained folate supplements from other sources. In addition, there was no control of potential confounding factors (except in that cases and controls were matched on general practitioner), and multiple comparisons were performed with no prior stated hypothesis, so the results must be judged with caution.

In 1988, the first population based case-control study of neural defects and periconceptional multivitamin supplementation was published. ${ }^{7}$ The study, conducted in Atlanta, USA, collected information on vitamin use for the three months before pregnancy and for the first three months of pregnancy, by telephone interview of the mothers up to 16 years after the birth of the index infant. Cases and controls were stratified by year of birth, so the mothers of both were recalling over similar periods of time. Only those mothers taking multivitamins every month for the entire six month period were considered as supplemented (14\% of the subjects). Comparisons were made with those mothers not taking any vitamin over that period $(40 \%$ of subjects), and an odds ratio of $0.4(95 \%$ CI $0.25,0.63)$ was obtained. Results were similar when cases were compared with a group of controls with other malformations. The major drawbacks of this study were the potential for recall bias, the absence of detail about the composition of the vitamin supplements consumed, and the effect of partial supplementation over the six month period. Vitamin users in the study were different from non-users in a number of demongraphic, health related, and lifestyle factors and although the known differences were adjusted for in the analysis, the effect seen may have been due to some unknown difference other than the taking of vitamins.

The Atlanta study can be compared with the study from the National Institutes of Child Health and Human Development in the USA. ${ }^{8}$ This case-control study found no association of neural tube defects and periconceptional vitamin supplementation with either multivitamins or folate. Information was also obtained on the vitamin content of cereals consumed by the mothers, and the vitamin intake was assessed in two ways: from tablets only, and from tablets plus cereals. All odds ratios were close to one, and the $95 \%$ confidence intervals for all of them were narrow, and embraced unity. There were two control groups: one of normal infants and one of

Table IV Comparison of Western Australian (WA) and USA data ${ }^{8}$ for periconceptional folate intake

\begin{tabular}{|c|c|c|c|c|}
\hline & $\begin{array}{l}U S A \\
\text { cases }\end{array}$ & $\begin{array}{l}W A \\
\text { cases }\end{array}$ & $\begin{array}{l}\text { USA } \\
\text { controls }\end{array}$ & $\begin{array}{l}\text { WA } \\
\text { controls }\end{array}$ \\
\hline $\begin{array}{l}\text { RDA for folate } \\
\text { Supplements only } \\
\text { Supplements + cereals } \\
\text { Supplements + diet }\end{array}$ & $\begin{array}{l}11 \cdot 9 \% \\
12 \cdot 2 \% \\
\mathrm{na}\end{array}$ & $\begin{array}{l}0 \\
\text { na } \\
13.3 \%\end{array}$ & $\begin{array}{l}11 \cdot 3 \% \\
12 \cdot 2 \% \\
\text { na }\end{array}$ & $\begin{array}{l}4 \cdot 7 \% \\
\text { na } \\
18 \cdot 7 \%\end{array}$ \\
\hline $\begin{array}{l}<\text { RDA for folate } \\
\text { Supplements only } \\
\text { Supplements + cereals } \\
\text { Supplements + diet }\end{array}$ & $\begin{array}{l}5 \cdot 8 \% \\
45 \cdot 0 \% \\
\text { na }\end{array}$ & $\begin{array}{l}14 \cdot 6^{\circ} \% \\
\text { na } \\
86 \cdot 7^{\circ} \%\end{array}$ & $\begin{array}{l}6 \cdot 9 \% \\
48 \cdot 5 \% \\
\text { na }\end{array}$ & $\begin{array}{l}10 \cdot 0^{\circ} \\
\text { na } \\
81 \cdot 3{ }^{\circ}\end{array}$ \\
\hline $\begin{array}{l}\text { No folate supplementation } \\
\text { No supplements } \\
\text { No supplements or cereals }\end{array}$ & $\begin{array}{l}82.3 \% \\
42.8 \%\end{array}$ & $\begin{array}{l}85 \cdot 4^{\circ} \% \\
\text { na }\end{array}$ & $\begin{array}{l}81.8 \% \\
39 \cdot 3 \%\end{array}$ & $\begin{array}{l}85 \cdot 3^{\circ}{ }_{o} \\
\text { na }\end{array}$ \\
\hline
\end{tabular}

$\mathrm{RDA}=$ recommended daily allowance; na $=$ not available infants with other malformations. The results were similar for both groups. It is not clear from the paper what exactly the time period criterion was for considering a women as supplemented, but it appears to be 30 days before the last menstrual period to 45 days after it, with vitamin supplements on six days or more a week. If the multivitamin supplement contained at least the USA recommended daily allowance (RDA) of at least four vitamins, then the woman was defined as fully supplemented, and if less than the RDA, she was defined as partially supplemented. It is not stated whether the RDA used were for pregnant or non-pregnant women. Women who began taking supplements in the critical period appear to have been considered unsupplemented. ${ }^{9}$ Misclassifying women who began supplements during the first few weeks of pregnancy, or women taking supplements for less than six days per week, as unsupplemented may have biased the odds ratios toward the null. Concerns about misclassification and selection bias in the study of Mills $e t a l^{8}$ have been recently been raised by Milunsky $e t a^{13}$ and Mulinare $e t$ $a l .{ }^{14}$

Assuming that the RDA for folate is $40 \mu \mathrm{g}$ (in Australia this is the RDA for pregnant women), then the Western Australian data and the US data (using the normal controls) can be compared as shown in table IV. Cereals in Australia are not fortified with folate, as folic acid is not a permitted vitamin under the Health Act (Health [Food Standard] [General] Regulations 1987; A9). A much smaller percentage of Western Australian cases and controls were taking the RDA or greater in folate supplements compared with USA subjects, and a similar proportion of cases and slightly more controls were over the RDA for diet and supplements combined for Western Australian mothers, compared with cereals and supplements combined for USA mothers. Since USA mothers would presumably obtain even more folate from the remainder of their diet, this implies that many more mothers in the USA study than in the Western Australian one had a high folate intake. Does this mean that low folate intake is so rare as not to be a major risk factor for neural tube defects in the American population? While this may be an explanation of the differences between the Western Australian study and the study of Mills et al, it may not explain the discrepancy between the two American studies. However, any multivitamin use in the normal controls was greater in the study of Mills et al than the Atlanta study $\left(19.6^{\circ}\right.$ versus $\left.14.5^{\circ}{ }_{0}\right)$, and neural tube defect prevalence has fallen in the period between the two studies. Thus there may have been a group of preventable neural tube defects at the time of the earlier study that was not present later. ${ }^{8}$

If folate is important in the prevention of neural tube defects, then the addition of the vitamin to breakfast cereals in the USA but not in Australia may be a partial explanation of the lower prevalence of the condition in the USA compared with Australia (around 1 per 1000 in the USA; and around 2 per 1000 in Australia). ${ }^{81516}$

A prospective study of diet and vitamin supplementation in a cohort of pregnant women, mainly from Massachusetts was published in 
1989. ${ }^{9}$ Women were ascertained at the time they underwent prenatal testing by maternal serum $\alpha$ fetoprotein screening. The majority of interviews took place before the women knew the result of the test, and hence the ascertainment of exposure was unlikely to have been biased by knowing the outcome of the pregnancy. Information on vitamin supplementation in the three months before and three months after conception was collected by telephone interview from 23491 women. Complete information was available for 22776 women, 49 of whom subsequently had an infant with a neural tube defect.

Comparing women who took multivitamins before conception and in the first trimester with women not taking supplements gave a prevalence ratio of $0.36(95 \%$ CI $0 \cdot 15,0.83)$. For users in the first six weeks of pregnancy, the prevalence ratio was $0.32\left(95^{\circ}{ }_{0}\right.$ CI $\left.0.15,0.66\right)$, while for women who started taking multivitamins after six weeks of pregnancy had elapsed, the prevalence ratio was $0.91(95 \% \mathrm{CI} 0.45,1.80)$. Comparing women who took multivitamins at least once per week in the first trimester only with those who took no multivitamins, the prevalence ratio of having an infant with a neural tube defect was $0.68(95 \%$ CI $0.34,1.35)$. When multivitamin use was subdivided into those supplements containing and not containing folate, the protective effect was found to be confined largely to folate supplementation. For women who knew the result of their prenatal tests, the protective effect was somewhat less marked than for those who did not know their results at the time of interview.

A third of women in the study were said to have begun vitamin supplementation in the first six weeks of pregnancy. Health conscious women, who may be at lower risk of having offspring with neural tube defects, may have contacted their doctor early in pregnancy and been prescribed prenatal vitamins (which all contain folate). If this occurred after neural tube closure but was recorded as being in the first six weeks, then the misclassification would have produced, spuriously, the association seen in this study. ${ }^{17}$ Misclassification of cases is also possible. The mothers of cases with multiple defects were not excluded from the analyses, and yet some of them (for example the three cases with chromosomal anomalies) are unlikely to have been due to inadequate folate/vitamin intake. Depending on the supplementation status of these cases, the prevalence ratios could be increased or decreased.

Similar results obtained from studies with different methodologies and different populations lend credence to the finding of an association of neural tube defects and vitamins, but only if the biases are different. The major advantage of the study of Milunsky et $a l^{9}$ over all the case-control studies was that the ascertainment of exposure occurred before knowledge of the outcome of pregnancy, largely obviating the potential for recall bias.
Further observational studies may shed some light on the association of neural tube defects and diet and/or vitamins, although they are likely to be hampered by recall bias to a greater extent than in the previous studies, since knowledge of the alleged association is even more widespread. The best evidence must now come from well designed and carefully conducted randomised controlled trials of recurrence and occurrence of neural tube defects, such as the Medical Research Council multicentre recurrence trial ${ }^{18}$ and the occurrence trial in Hungary. ${ }^{19}$

We thank Jan Payne, Melanie Honnor, Jane Doyle, Edwina Rudy, Rosemary Johnston, and Robin Forbes, who collected, coded, and entered the data; and $\mathrm{Dr}$ Dallas English, Dr Nick de Klerk, and Dr Bruce Armstrong for advice with the analysis. We are grateful to the mothers involved in the study who gave so willingly, and often at a time of great personal sadness. The study was funded by the TVW-Telethon Foundation.

1 Smithells RW, Sheppard S, Schorah CJ, et al. Possible prevention of neural tube defects by periconceptionl vitamin supplementation. Lancet 1980; i: 339-40.

2 Smithells RW, Sheppard S, Schorah CJ, et al. Apparent prevention of neural tube defects by periconceptional prevention of neural tube defects by periconceptional
vitamin supplementation. Arch Dis Child 1981; 56: 911-8.

3 Sithithells RW, Seller MJ, Harris R, et al. Further experience of vitamin supplementation for prevention of neural tube of vitamin supplementation for prevention of
defect recurrences. Lancet 1983 ; i: 1027-31.

4 Smithells RW, Sheppard S, Wild J, Schorah CJ. Prevention of neural tube defect recurrences in Yorkshire: final report. Lancet 1989; ii: 498-9.

5 Laurence KM, James N, Miller MH, Tennant GB, Campbell $\mathrm{H}$. Double-blind randomised controlled trial of folate treatment before conception to prevent recurrence of neural-tube defects. BMF 1981; 282: 1509-11.

6 Wald NJ, Polani PE. Neural-tube defects and vitamins: the need for a randomized clinical trial. Br $\mathcal{f}$ Obstet Gynaecol $1984 ; 91 ; 516-23$.

7 Mulinare J, Cordero JF, Erickson JD, Berry RJ. Periconceptional use of multivitamins and the occurrence of neural tube defects. $¥ A M A 1988 ; 260: 3141-5$.

8 Mills JL, Rhoads GG, Simpson JL, et al. The absence of a relation between the periconceptional use of vitamins and relation between the periconceptional use of vitamins
neural-tube defects. $N$ Engl $f$ Med 1989; 321: 430-5.

9 Milunsky A, Jick H, Jick S, et al. Multivitamin/folic acid supplementation in early pregnancy reduces the prevalence of neural tube defects. $¥ A M A 1989 ; 262: 2847-52$.

10 Bower C, Stanley FJ. Dietary folate as a risk factor for neural tube defects: evidence from a case-control study in Western Australia. Med f Aust 1989; 150: 613-9.

11 Bower C, Stanley FJ. Western Australian Congenita Malformations Register. Med $\mathcal{f}$ Aust 1983; 2: 189-91.

12 Winship KA, Cahal DA, Weber JCP, Griffin JP. Maternal drug histories and central nervous system anomalies. Arch Dis Child 1984; 59: 1052-60.

13 Milunsky A, Jick H, Jick SS, Willet W. Periconceptional use of multivitamins and the prevalence of neural-tube defects. $N$ Engl f Med 1990; 322: 1082-3.

14 Mulinare J, Cordero JF, Erickson JD, Berry RJ. Periconceptional use of multivitamins and the prevalence of Periconceptional use of multivitamins and the prevalen

15 Bower C, Forbes R, Rudy E, Ryan A, Stanley F. Report of the Congenital Malformations Registry of Western Australia 1980-1988. Health Department of Western Australia, Statistical Series/16, Perth, 1989.

16 The South Australian Birth Defects Register. Annual report 1988. Adelaide: Adelaide Children's Hospital, 1990.

17 Mills JL, Rhoads GG, Hoffman HT, et al. Periconceptiona use of multivitamins and the prevalence of neural-tube defects. N Engl f Med 1990; 322: 1083-4.

18 Notes and News. MRC trial of multivitamin prophylaxis in pregnancies at risk of neural defects. Lancet 1982; ii: 1412.

19 Czeizel A, Rode K. Trial to prevent first occurrence neural $A$, Rode $K$. Trial to prevent first occurrence of supplementation. Lancet 1984; i: 40. 